Canada. National Hydrology Research Institute. (NHRI Science Report 4.)

Penck, A. 1894. Morphologie der Erdoberfläche. Stuttgart, J. Engelhorn.

SIR,

\section{A reply to comments by $G$. Kaser on "The use of planimetric surface area in glacier mass-balance calculations: a potential source of errors" by Jacobsen and Theakstone}

Dr Kaser makes three points in his comments on our paper: that surface area is a function of scale, and non-planimetric areas should not be used for calculations of mass balance and related topics; that mass-balance calculations involve a rhombus with two vertical and two inclined sides; and that "mass-balance glaciers" should be chosen carefully, to avoid those which are not "suitable". We consider that, in part, Dr Kaser's remarks illustrate the difference between what is theoretically ideal and what is the best that can be achieved in the real world.

We agree that surface area is scale-dependent. Indeed, we noted that "the true surface area is always larger than that which is calculated, even when a very accurate DTM is used, and the surface roughness, represented by the ratio of the planimetric area to the 'true' surface area, is lower than that actually present on the glacier" Jacobsen and Theakstone, 1995). (We should, perhaps, have written "true" throughout our paper.) Nevertheless, we wish to emphasise that, in calculations relating to the use of water resources in glacierized areas, the best possible representation of the surface area on which snow accumulates, or from which ice melts, should be used. For example, if a metre of ice melts from a dome-shaped area several hundred metres in diameter, the resultant loss of volume is better calculated for engineering purposes by using the surface area of a hemisphere rather than that of a circle.

Whilst an element of planimetric area can be calculated from an element of surface area by multiplying the latter by the cosine of the local surface slope, the definition of the latter is limited by the detail which can be extracted from available maps. In drawing attention to the potential value of three-dimensional digital terrain models, we hoped to emphasise the degree to which, with modern techniques of surveying, it is possible to produce better maps of glaciers than those based on older methods. Thus, global positioning systems make it possible to acquire three-dimensional (elevation and geographical-coordinate) data from a very large number of points in a relatively short period (Hulbe and Whillans, 1994). The maps which can be produced from such data are much more accurate than those used previously. This is particularly the case for featureless areas, such as those parts of a glacier which are permanently covered by snow, for which there are inherent difficulties in plotting photogrammetric contours (Ostrem, 1966). Within a GIS, the aspect and gradient of every triangular facet in a TIN DTM can be determined simply, and areas which are shaded by adjacent terrain for different solar elevations and azimuth can be identified. Such information is likely to be of value in energy-balance calculations, despite Dr
Kaser's reservations. In computing the ablation and consequent discharge generated by energy inputs to the surface of a glacier where slopes are of different steepness and exposure, measurements of heat-balance components at a point on a horizontal surface cannot give results which relate to the entire glacier.

Whilst, in theory, the point values of ablation at stakes and snow depths determined by probing during mass-balance studies should be measured vertically, it is unusual for this to be done in practice. Ablation stakes almost invariably tilt, even if care is taken to ensure that they are vertical when first set in place. In mass-balance programmes, snow accumulation usually is determined by several hundred measurements, frequently made by an individual moving across the glacier on skis. In those circumstances, the measured depth is as likely to be normal to a gently inclined surface as vertical. Nice though it would be to convert all such field measurements to truly vertical values, it is unlikely that the results would justify the effort involved. In the real glaciological world, the theoretical rhombus does not feature!

Most glacier mass-balance programmes are carried out for a particular purpose. In Norway, hydropower planning is the basis for such investigations. However, few Norwegian glaciers possess an ideal textbook mass-balance geometry: more typical of areas in which glaciers play a significant role in the use of water resources are those, such as Nigardsbreen (Jostedalen), Engabreen (Svartisen) and Austre Okstindbreen (Okstindan), which are of the "plateau" type, with a steeper, often broken, section intervening between their higher and lower parts (Haakensen, 1995). It is on these glaciers, seracs and rough surfaces included, rather than on atypical "ideal" glaciers, that mass-balance measurements have been, and will continue to be, made by practical glaciologists. In making the most of their field data, they should endeavour to relate them to the best available representation of the actual form of the glacier surface. Here, digital terrain models are likely to provide more useful data than simple measures of planimetric area.

Department of Geography, University of Manchester, Manchester M13 9PL, England

\section{April 1996}

\section{REFERENGES}

Haakensen, N., ed. 1995. Glasiologiske undersokelser i Norge 1992 og 1993. Norges Vassdrags- og Energiverk. Hydrologisk Avdeling 08.

Hulbe, C. L. and I. M. Whillans. 1994. Evaluation of strain rates on Ice Stream B, Antarctica, obtained using GPS phase measurements. Ann. Glaciol., 20, $254-262$.

Jacobsen, F. M. and W.H. Theakstone. 1995. The use of planimetric surface area in glacier mass-balance calculations: a potential source of errors. 7. Glaciol., 41 139), 441-444.

Kaser, G. 1996. Correspondence. Comments on "The use of planimetric surface area in glacier mass-balance calculations: a potential source of errors" by Jacobsen and Theakstone. J. Glaciol., 42 142), 588.

Ostrem, G. 1996. Surface coloring of glaciers for air photography. Can. j. Earth Sci., 3(6), 877-880. 